\title{
Binding and activation of host plasminogen on the surface of Francisella tularensis
}

\author{
Shawn R Clinton, James E Bina, Thomas P Hatch, Michael A Whitt, Mark A Miller
}

\begin{abstract}
Background: Francisella tularensis (FT) is a gram-negative facultative intracellular coccobacillus and is the causal agent of a life-threatening zoonotic disease known as tularemia. Although FT preferentially infects phagocytic cells of the host, recent evidence suggests that a significant number of bacteria can be found extracellularly in the plasma fraction of the blood during active infection. This observation suggests that the interaction between FT and host plasma components may play an important role in survival and dissemination of the bacterium during the course of infection. Plasminogen (PLG) is a protein zymogen that is found in abundance in the blood of mammalian hosts. A number of both gram-positive and gram-negative bacterial pathogens have the ability to bind to PLG, giving them a survival advantage by increasing their ability to penetrate extracellular matrices and cross tissue barriers.

Results: We show that PLG binds to the surface of FT and that surface-bound PLG can be activated to plasmin in the presence of tissue PLG activator in vitro. In addition, using Far-Western blotting assays coupled with proteomic analyses of FT outer membrane preparations, we have identified several putative PLG-binding proteins of FT.

Conclusions: The ability of FT to acquire surface bound PLG that can be activated on its surface may be an important virulence mechanism that results in an increase in initial infectivity, survival, and/or dissemination of this bacterium in vivo.
\end{abstract}

\section{Background}

Francisella tularensis (FT) is a Gram-negative intracellular pathogen that is the etiological agent of a multi-syndromic disease with a high morbidity/mortality that is referred to as tularemia. The pneumonic form of tularemia is of particular concern because of the high mortality rate (up to $60 \%$ ) following inhalation of as few as ten organisms [1-4]. Francisella species are found throughout the Northern Hemisphere and infect a variety of vertebrate and invertebrate hosts $[5,6]$. Infections with FT can be contracted from blood sucking insects, such as the deer fly $[5,7]$, mosquitoes $[8,9]$, and ticks $[5,7,10]$, and by open-wound contact with infected animal tissue $[5,11,12]$.

Upon entry into a susceptible vertebrate host, FT is readily phagocytized by resident macrophages and dendritic cells and quickly escapes into the cytoplasm $[13,14]$ where it multiplies. Late in its replicative cycle,

\footnotetext{
* Correspondence: mamiller@uthsc.edu

Department of Molecular Sciences, The University of Tennessee Health Science Center, 858 Madison Avenue, Memphis, Tennessee 38163, USA
}

FT induces apoptotic death of the host phagocyte, resulting in release of progeny bacteria that can infect new host cells. Recent studies have shown that significant numbers of FT are found in the acellular plasma fraction of mice infected intradermally or intranasally with either FT Live Vaccine Strain (LVS) (Type B) or FT Schu S4 (Type A) [15], and intranasally with FT novicida [16]. These findings suggest that, in addition to utilizing the intracellular cytoplasmic niche for replication and protection from humoral immunity, FT may also have a significant extracellular phase. Several studies have shown that deposition of host complement component $\mathrm{C} 3$ on the surface of $\mathrm{FT}$ is required for opsonophagocytosis by activating CR3 and CR4mediated phagocytosis by macrophages and dendritic cells $[14,17,18]$. It is also known that FT is relatively resistant to complement-mediated lysis [19]. A recent report suggested that resistance of FT to membrane attack complex-mediated lysis may be due (at least in part) to its ability to bind to factor $\mathrm{H}$ from host plasma [20]. It is possible that the ability of FT to bind to factor 
$\mathrm{H}$ and potentially to other host plasma components plays a significant role in its pathogenesis.

It has been long established that a broad spectrum of both gram-positive and gram-negative bacterial pathogens gain a survival advantage by interacting with components of the host coagulation/fibrinolytic system in humans [21-24]. For instance, the ability to acquire surface-associated plasmin has been documented as an important virulence mechanism in Group A streptococci [25], Borrelia burgdorferi [26], and Yersinia pestis [27] by aiding in the organism's ability to penetrate the extracellular matrix and to disseminate to distal sites in the host. Plasminogen (PLG) is a $92-\mathrm{kDa}$ glycoprotein zymogen that is involved in fibrinolysis. This precursor protein is converted to an active serine protease (plas$\mathrm{min}$ ) by cleavage of the peptide bond between residues $\mathrm{R}^{560}$ and $\mathrm{V}^{561}$ in vivo via urokinase-type (uPA) and/or tissue-type (tPA) PLG activators. Plasmin has an important role in blood clot resolution because of its role in the degradation of fibrin polymers. Because plasmin has other substrates that include pro-collagenases, prometalloproteinases, and extracellular matrix proteins, such as fibronectin, laminin, and vitronectin, the ability of a bacterium to acquire surface-associated plasmin can result in an enhanced ability of the pathogen to penetrate the extracellular matrix and to disseminate to distal sites in the host $[21,23,25]$. In this report we show that PLG binds to the surface of FT in vitro and that surface-bound PLG can be converted to the active plasmin form. In addition, using a combination of Far-Western blotting analyses coupled with proteomic methodologies, we have identified several FT proteins that can bind to human PLG in vitro.

\section{Results}

\section{Binding of PLG from fresh human plasma to the surface} of FTLVS

We used an ELISA assay to determine that PLG in fresh frozen plasma (FFP) binds to FTLVS grown to mid-log phase in BHI (Figure 1). Binding was inhibited when $\varepsilon^{-}$ aminocaproic acid ( $\varepsilon A C A)$, known to inhibit binding of PLG to lysine groups in proteins, was included in the incubation mixture. To help eliminate the possibility of non-specific binding of PLG due to its high concentrations in human plasma and also to rule out the contributions of other plasma proteins, we used purified human Glu-PLG (huPLG) and noted similar results to those observed when FFP was used (Figure 2A). We also found that huPLG binds to the highly virulent Schu S4 strain of FT at moderately higher levels than observed with FTLVS (Figure 2B). We confirmed that binding of huPLG to FT is a lysine-dependent interaction by showing that increasing concentrations of $\varepsilon A C A$ can inhibit binding of huPLG to FTLVS in a dose-

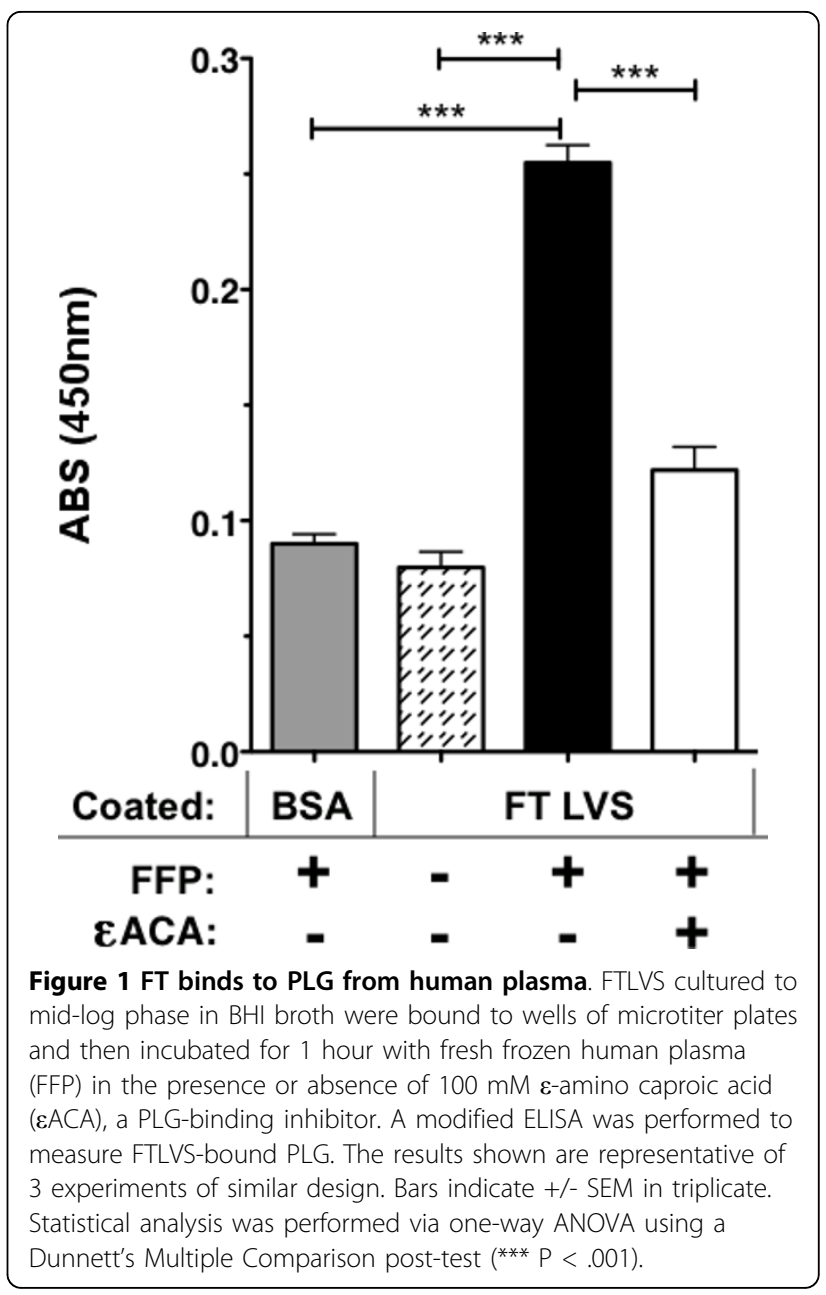

dependent fashion (Figure 3). When similar concentrations of glycine were used as an inhibitor control, no inhibition of huPLG binding was observed (data not shown). Confocal microscopic analyses suggested that huPLG binds to the surface of FT (Figure 4); however, it is possible that some of the staining observed was the result of huPLG penetration into the outer envelope of FT. Although is has been reported that culture media composition can have a significant impact of the surface properties and virulence characteristics of FTLVS [28], we observed no differences in the ability of PLG to bind to the surface of FTLVS grown in modified MuellerHinton medium vs. brain-heart infusion broth (data not shown).

\section{Plasmin activation on the surface of FT LVS in vitro by a PLG activator}

In other bacterial systems, surface-bound PLG can be converted to its proteolytically active plasmin form that contributes to the organism's virulence [21-24]. To test whether huPLG bound to FTLVS can be converted to plasmin, we used a chromogenic plasmin substrate 

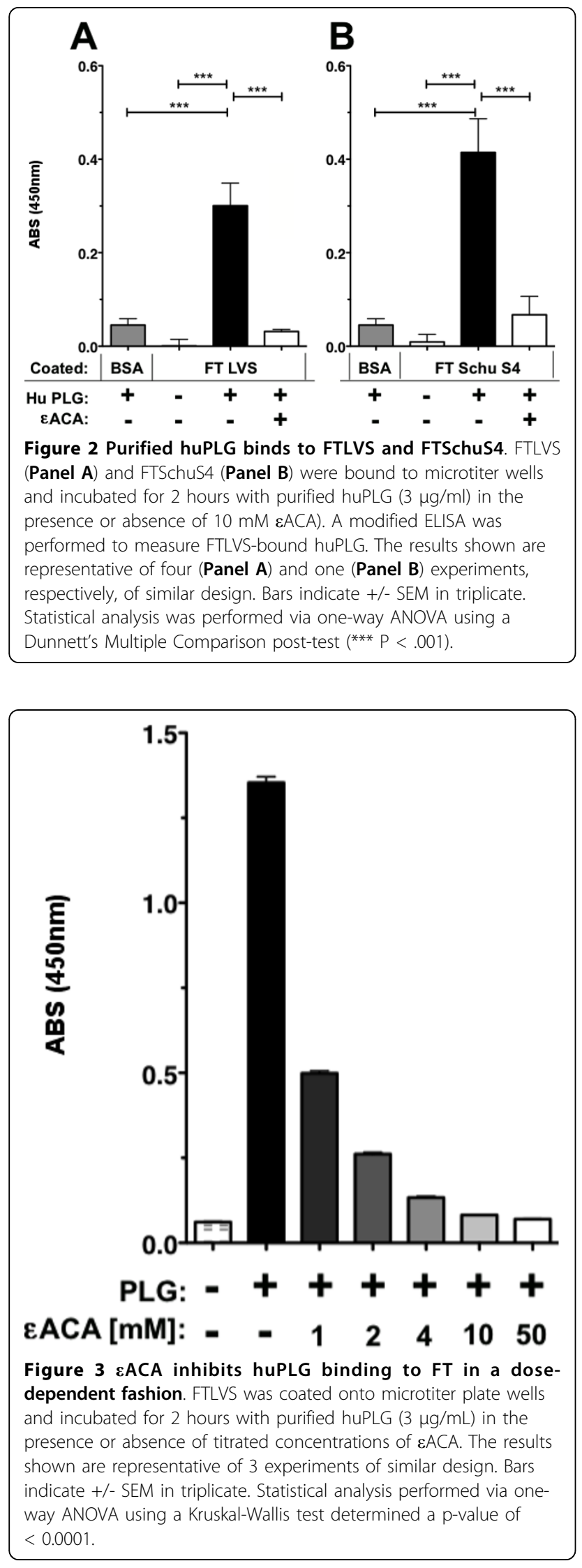

(H-D-Val-Leu-Lys-pNA) to detect proteolytic activity following the addition of tissue PLG activator (tPA) (Figure 5). We also found that plasmin on the surface of FT can break down fibronectin (Figure 6), suggesting that FT-bound plasmin can potentially participate in the degradation of extracellular matrices.

\section{Identification of putative Francisella PLG-binding membrane proteins}

We used Far-Western Blot methodology and mass spectrometry to identify potential PLG receptors in the Sarkosyl soluble and insoluble FTLVS membrane fractions (Figure 7). Sarkosyl is a weak anionic detergent in which many outer membrane proteins of Gram-negative bacteria are insoluble [29]. We transferred the Sarkosyltreated proteins to a PVDF membrane and incubated the membrane with PLG and identified bound PLG by reaction with anti-PLG mAbs (Figure 7a). We used the relative migration rates of the reactive bands to identify the reactive proteins on a duplicate Coomassie-stained polyacrylamide gel (Figure $7 b$ ), which were then excised for proteomic analysis by mass spectrometry. Several prominent PLG-binding proteins were noted in the total membrane fraction of FTLVS, all but one of which was found in the Sarkosyl insoluble fraction (Figure 7b). The identity of the prominent proteins from this assay (Figure $7 \mathrm{c}$ ) are the products of the following genes: FTL_1328 (outer membrane associated protein, fopA1), FTL_1042 (FKBP-type peptidyl-prolyl cis-trans isomerase family protein), FTL_0336 (peptidoglycan-associated lipoprotein), FTL_0421 (hypothetical lipoprotein, lpn-A), and FTL_0645 (hypothetical lipoprotein).

\section{Discussion}

Until recently FT has been considered an intracellular pathogen whose dissemination to tissues distal to the site of initial infection was highly dependent on its ability survive within host macrophages. The observation that FT can be found in relatively high numbers in the acellular plasma fraction of its mammalian host $[15,16]$ suggested that FT may have a significant extracellular component to its life cycle and that interactions between FT and one or more plasma proteins could contribute to its ability to disseminate within the host. There are a number of examples of bacterial pathogens that utilize interactions with host plasma components to enhance their ability to colonize and to penetrate the extracellular matrices of host cells/tissues. A wide range of bacterial pathogens (including Francisella) subvert the destructive mechanisms of the complement cascade by acquiring surface-bound complement control proteins [20,30-34]. Moreover, a number of Gram-positive bacterial pathogens including streptococcal spp. [35,36], staphylococcal spp. [37-40], and Bacillus anthracis [41,42], 


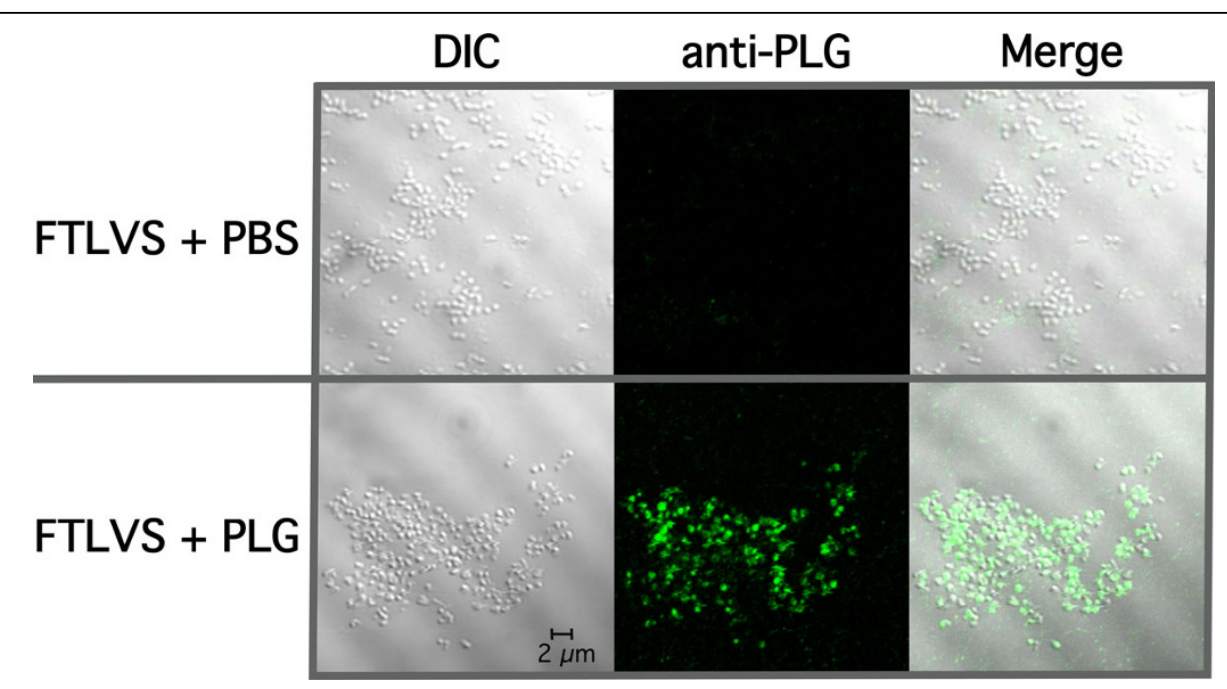

Figure 4 PLG binds to the outer envelope of FT. Laser scanning confocal microscopy of PLG-associated FTLVS was performed as described in "Materials and Methods". Bound huPLG ligand was detected using sheep anti-human PLG antibody followed by incubation with Dylight-488 conjugated donkey, anti-sheep/goat lgG secondary antibody. Samples were visualized using a Zeiss LSM 510 confocal microscope.
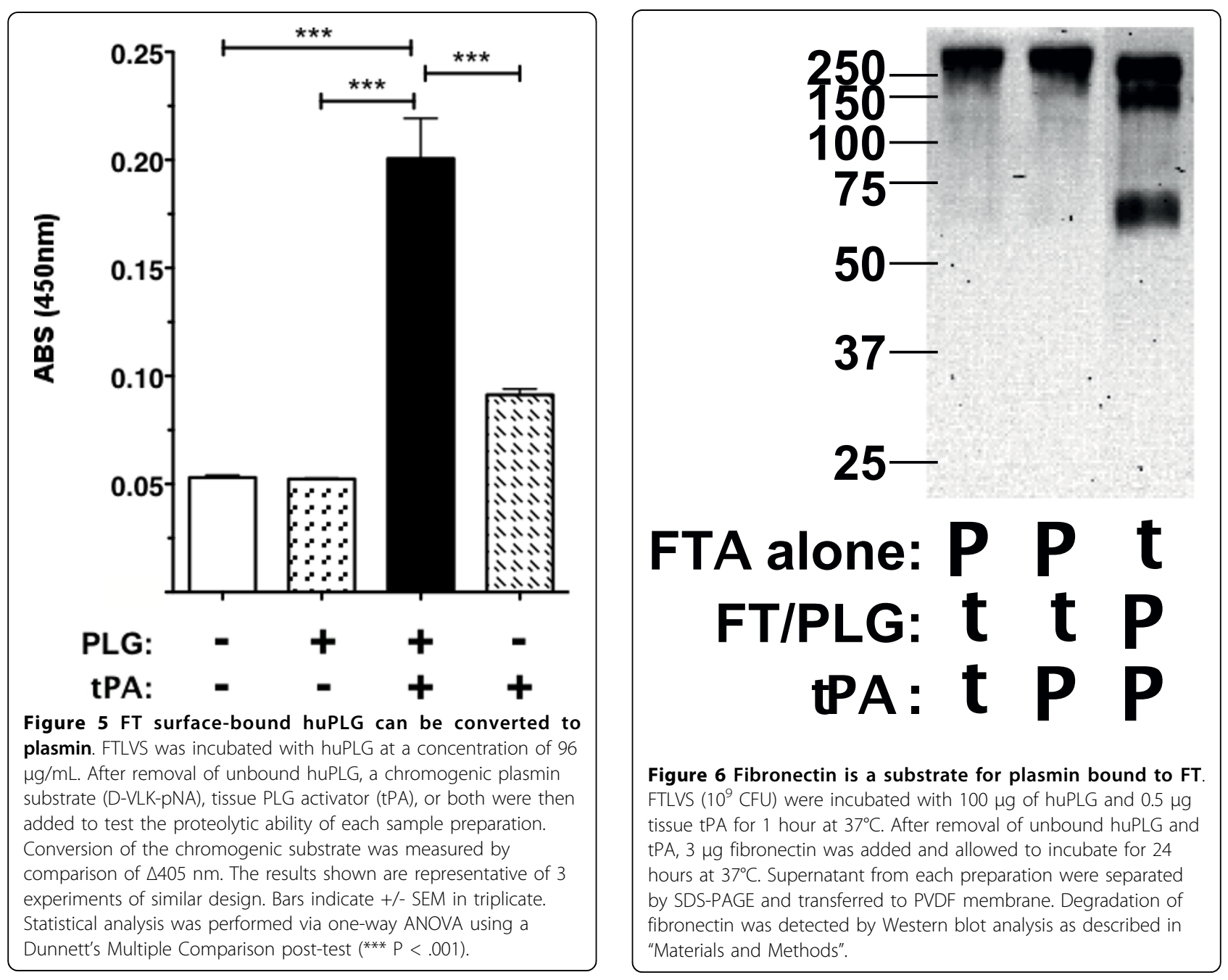


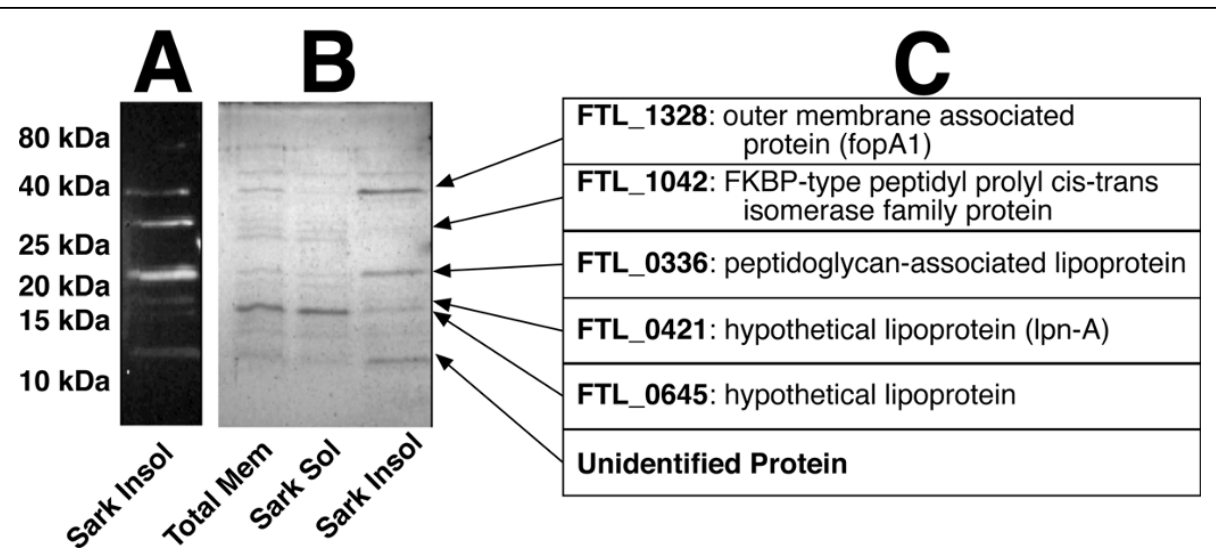

Figure 7 Identification of putative PLG-binding proteins of FT. Sarkosyl-soluble and insoluble protein fractions of FTLVS were separated by SDS-PAGE and transferred to PVDF membrane. Membranes were then blotted with huPLG ( $3 \mathrm{ug} / \mathrm{mL})$ followed by anti-PLG antibody and HRPconjugated secondary antibody to detect PLG-binding proteins (Panel A). Protein bands on an identical Coomassie Blue-stained SDS-PAGE gel corresponding to those identified via blotting (Panel B) were excised and identified using proteomic methodologies (Panel C).

as well as Gram-negative bacteria such as Pseudomonas aeruginosa [43] have been shown to augment their invasive capacity by interacting with fibrinogen, fibronectin, and/or PLG. Yersinia pestis is probably the best-characterized example of a pathogen that exploits the host fibrinolytic system to penetrate host tissues. Yersinia expresses a surface serine protease (designated Pla) whose substrates include several complement components, PLG, and alpha2-antiplasmin (the primary circulating inhibitor of plasmin). Pla also has adhesin activity and binds to laminin (a glycoprotein of mammalian basement membranes). Because Pla upregulates plasmin activity, and because laminin is a substrate of plasmin, Yersinia can very efficiently penetrate basement membranes of host tissues [for review, see Suomalainen et. al. [44]]. Clearly, interaction with plasma components is a strategy that is used by many bacterial pathogens to gain a survival advantage within their hosts.

The goal of the studies described here was to determine whether FT has the potential to use the host fibrinolytic system (specifically PLG) to enhance its ability to penetrate/disseminate following infection of a mammalian host. Our results indicate that both FTLVS and FTSchuS4 are able to acquire surface bound PLG in vitro and that this zymogen can be converted by a hostderived PLG activator into its active serine protease form (plasmin) while bound to FTLVS. The ability of PLG to bind its ligands typically involves its lysine-binding kringle domains. This specific interaction between PLG and exposed lysine residues can be inhibited with the lysine-analogue $\varepsilon A C A$ and, to a lesser extent, with free lysine. Our findings revealed that binding of PLG to the surface of FTLVS could be inhibited by \&ACA in a dose-dependent fashion. Moreover, we showed that plasmin bound to the surface of FT could degrade fibronectin. This finding supports our hypothesis that the ability of FT to bind to serum plasmin may enhance its ability to penetrate extracellular matrices, enhancing its ability to disseminate in vivo.

Using a ligand-blotting technique coupled with proteomic methodologies we identified five FTLVS proteins that were able to bind to PLG, each of which are highly conserved among the various FT type A and B strains. Three of these proteins are lipoproteins (gene products of FTL_0336, FTL_0421, and FTL_0645). Two of the lipoproteins are unique to FT, while the third, peptidoglycan-associated lipoprotein (PAL), is highly conserved among gram-negative bacteria. The specific use of surface-exposed lipoproteins as receptors for host PLG is not unusual and has been well documented in other human bacterial pathogens, such as some members of the genus Borrelia and Treponema. Several members of the genus Borrelia use complement regulator-acquiring surface proteins (CRASP) to bind both PLG and complement factor $\mathrm{H}$ to aid in the ability of the organism to both disseminate and to resist innate immunity [45-50]. An additional example of a PLG-binding lipoprotein is OppA of Treponema denticola, which has been suggested to play a role in periodontal disease in humans [51]. With this in mind, there lies the possibility that lipoproteins of Francisella species may have the capacity to bind multiple host-derived proteins in addition to PLG.

Here we have shown that FT can bind to PLG and that surface-bound PLG can be activated by tPA to its proteolytic form (plasmin). The binding of PLG on the surface of FT could play a role in several phases of tularemia, including the initial entry into the host through insect bites and/or broken skin where active fibrinolytic processes would provide an early 
opportunity for FT to acquire proteolytic activity that might augment the establishment or dissemination of infection. During later phases of tularemia the acquisition of plasmin on the cell surface may contribute to its pathogenicity by degrading host innate effector molecules and extracellular matrix components. Based on the new report that FT-bound plasmin can degrade immunoglobulins [52], as well as the established ability of FT to acquire surface-bound factor $\mathrm{H}$ [20], it also appears likely that FT uses plasma components to interfere with host humoral immune mechanisms throughout the course of FT infection. Future studies to identify additional plasma components that can be surface acquired by FT may uncover additional virulence mechanisms used by this pathogen during its extracellular life cycle.

\section{Conclusions}

FT interacts with at least two serum components (plasmin, and complement factor $\mathrm{H}$ ), and it seems likely that FT also uses interactions with additional host serum components to gain a survival advantage. Our lab is examining FT interactions with additional targets, including fibrinogen and fibronectin, both of which are substrates for plasmin and are host components that are known to be exploited by numerous pathogens for adhesion to and penetration of extracellular matrix layers. The interaction of FT with host serum components may play a significant role in the survival and dissemination of this highly pathogenic bacterium. Gaining a better understanding of these interactions could be a critical step in the development of therapeutic and prophylactic interventions for tularemic disease.

\section{Methods}

\section{Bacterial strains and culture}

F. tularensis Live Vaccine Strain (FTLVS) was a kind gift of Dr. Karen Elkins (FDA, Bethesda, MD). FT Schu S4 was obtained from the CDC. All bacterial cultures were grown overnight in Brain-Heart Infusion broth $(37 \mathrm{~g} / \mathrm{L}$, $\mathrm{pH}$ 6.8) from frozen stocks at $37^{\circ} \mathrm{C}$ with shaking to mid$\log$ phase $\left(\mathrm{OD}_{600}=\sim 0.7\right)$ before use.

\section{Reagents}

Human fresh frozen plasma (FFP) was purchased from Lifeblood Mid-South Regional Blood Center (Memphis, TN). Purified human Glu-PLG (huPLG), human singlechain tissue PLG activator (tPA), and the plasmin colorimetric substrate (H-D-Val-Leu-Lys-pNA) were purchased from Molecular Innovations (Novi, MI). Bovine serum albumin (fraction V) was purchased from Thermo-Fisher Scientific (Pittsburgh, PA). Polyclonal sheep anti-human PLG, anti-human fibronectin, and donkey anti-sheep/goat IgG:Dylight-488 antibody preparations purchased from AbD Serotec (Raleigh, NC).
Monoclonal anti-goat/sheep IgG-horseradish peroxidase conjugated secondary antibody (clone GT-34) and $\varepsilon$-aminocaproic acid (A7824) were purchased from Sigma-Aldrich (St. Louis, MO). Ninety-six well MAXISORP ELISA plates were purchased from Nunc (Rochester, NY).

\section{PLG binding ELISA assays}

FTLVS was cultured overnight to mid-log phase, pelleted at $6,400 \times \mathrm{g}$ for 30 minutes, washed twice with phosphate-buffered saline (PBS), and resuspended in PBS with $0.1 \% \mathrm{Na}$ azide to an $\mathrm{OD}_{600}=0.1$. The resulting bacterial suspension was added to microtiter plates $(100 \mu \mathrm{L} /$ well; approximately $2.5 \times 10^{8}$ bacterial cells) before being incubated overnight at $4^{\circ} \mathrm{C}$ to facilitate binding. The wells were then washed twice with $200 \mu \mathrm{L}$ of Tris-buffered saline (TBS) pH 7.45 containing $0.05 \%$ Tween-20 (TBST) to remove unbound bacteria and then pre-blocked with 200 $\mu \mathrm{L}$ of TBST containing $1 \%$ bovine serum albumin (1\% BSA-TBST) for 1 hour at $\mathrm{RT}^{\circ}$ to prevent non-specific protein binding. After removal of the blocking solution, $90 \%$ citrated human plasma or $3 \mu \mathrm{g} / \mathrm{mL}$ huPLG in $1 \%$ BSA-TBST was added to each well $(100 \mu \mathrm{L})$, with or without the indicated concentrations of $\varepsilon$-amino caproic acid (EACA), and incubated for $1-2$ hours at $37^{\circ} \mathrm{C}$ with gentle rocking. Wells were washed three times with TBST and then sheep anti-human PLG-specific antibody (1:2,000 dilution in $1 \%$ BSA-TBST) was added $(100 \mu \mathrm{L} /$ well) and allowed to incubate for 1 hour at $37^{\circ} \mathrm{C}$. Unbound primary antibodies were removed by washing three times with TBST, followed by the addition of HRPconjugated anti-sheep/goat IgG mAb (GT-34, 1:5,000 dilution in $1 \%$ BSA-TBST; $100 \mu \mathrm{L} /$ well) and incubation for 1 hour at $37^{\circ} \mathrm{C}$. Unbound secondary antibodies were removed by washing four times with TBST, and OptEIA TMB colorimetric substrate solution (Becton-Dickenson, Franklin Lakes, NJ) was added to each well $(100 \mu \mathrm{L} /$ well $)$ and incubated at $37^{\circ} \mathrm{C}$ for $20 \mathrm{~min}$. to allow color development. Absorbance at $450 \mathrm{~nm}$ was determined using a SpectraMAX 340 plate reader (Molecular Devices, Sunnyvale, CA).

\section{Indirect immunofluorescence assays}

FTLVS was cultured and washed as described above. After diluting the washed bacteria to $\mathrm{OD}_{600}=0.1,1 \mathrm{~mL}$ aliquots were incubated with a total of $40 \mu$ gs of PLG or PBS (negative control) for 30 minutes at $37^{\circ} \mathrm{C}$ with gentle rotation. Bacteria were then washed three times with PBS by centrifugation, resuspended in $100 \mu \mathrm{L}$ of PBS, followed by spotting $20 \mu \mathrm{L}$ of each sample onto glass coverslips. The samples were then air-dried overnight at $37^{\circ} \mathrm{C}$. After methanol fixation, the coverslips were blocked with $1 \%$ BSA-PBS at room temperature before adding sheep anti-human PLG (1:100 diluted in 1\% 
BSA-PBS) for 30 minutes at room temperature. The coverslips were gently washed with PBS before adding donkey anti-sheep/goat IgG:Dylight-488 (1:100 diluted in $1 \%$ BSA-PBS), followed by incubation for 30 minutes at room temperature. After washing again with PBS, coverslips were mounted onto glass slides using 100\% glycerol containing $0.1 \mathrm{M}$ n-propyl gallate and images were collected on a Zeiss LSM 510 confocal microscope with an Axiovert $100 \mathrm{M}$ base with a $100 \times$ Plan Apochromat 1.4 NA oil DIC objective using the argon laser for $488 \mathrm{~nm}$ excitation and 505-530 $\mathrm{nm}$ bandpass emission filter for imaging Dylight488 fluorescence and the HeNe1 $543 \mathrm{~nm}$ laser for illumination of the DIC images. Both images were collected using identical detector gain and amplifier offset settings, and the images shown are $1.0 \mu \mathrm{m}$ optical slices. Digital images were visualized using Zeiss AxioVision LE software.

\section{Chromogenic plasmin activation assay}

FTLVS was cultured overnight to mid-log phase, washed twice with TBS and then resuspended in TBS to an $\mathrm{OD}_{600}$ of 0.7. Aliquots of the bacterial suspension $(50 \mu \mathrm{L})$ was added to $50 \mu \mathrm{L}$ of TBS alone or TBS containing huPLG $(192 \mu \mathrm{g} / \mathrm{mL})$ and incubated for 1 hour at $37^{\circ} \mathrm{C}$. The cells were washed $3 \times$ with TBST containing $0.1 \% \mathrm{BSA}$, and pellets were resuspended in $200 \mu \mathrm{L}$ of TBS and then split into two $100 \mu \mathrm{L}$ aliquots. $50 \mu \mathrm{L}$ of $50 \mathrm{mM}$ Tris- $\mathrm{HCl}(\mathrm{pH}$ 7.45) with or without $333 \mu \mathrm{M}$ of the chromogenic plasmin substrate (H-D-Val-Leu-LyspNA) and $50 \mu \mathrm{L} 1.2 \mu \mathrm{g}$ of tPA or TBS alone was added to each sample and incubated at $37^{\circ} \mathrm{C}$ for $3 \mathrm{~h}$. Bacteria were pelleted via centrifugation and $150 \mu \mathrm{L}$ of each supernatant was pipetted into a 96-well plate and absorbance at $405 \mathrm{~nm}$ was determined as a measure of plasmin activity.

\section{Membrane protein fractionation}

Outer membrane enriched fractions were isolated by a procedure adapted from de Bruin, et al [53]. FTLVS were grown in BHI broth $(500 \mathrm{ml})$ to mid-log phase and then were pelleted via centrifugation at $6,400 \times \mathrm{g}$ for 30 minutes. Cells were resuspended in cold PBS and then lysed by sonication. Unlysed bacterial cells were separated from the whole-cell lysate by centrifugation at $10,000 \times \mathrm{g}$ for 20 minutes at $4^{\circ} \mathrm{C}$. The insoluble membrane fraction was then isolated by ultracentrifugation for 1 hour at $100,000 \times \mathrm{g}$ at $4^{\circ} \mathrm{C}$. After removal of the soluble protein fraction, the pelleted total membrane fraction was resuspended in $1 \%$ sarkosyl with vortexing and subjected to a second round of ultracentrifugation for 1 hour at $100,000 \times \mathrm{g}$ at $4^{\circ} \mathrm{C}$. The Sarkosyl-insoluble pellet was resuspended in $50 \mathrm{mM}$ Tris $\mathrm{pH}$ 8. The protein concentration of both the Sarkosyl-soluble and Sarkosyl-insoluble fractions was determined using the DC protein assay (Bio-Rad, Hercules, CA) according to manufacturer directions. Samples were stored at $-20^{\circ} \mathrm{C}$ until use.

\section{Fibronectin degradation assay}

Overnight cultures of FTLVS were washed three times with PBS, $10^{9} \mathrm{CFU}$ were pipetted into $1.5 \mathrm{~mL}$ tubes, and bacteria were pelleted via centrifugation at $18,900 \times \mathrm{g}$ for 10 minutes. Bacterial pellets were then resuspended in $50 \mu \mathrm{l}$ of PBS with or without PLG $(2 \mathrm{mg} / \mathrm{ml})$, followed by the addition of $50 \mu \mathrm{l}$ of tPA $(10 \mu \mathrm{g} / \mathrm{mL})$ and incubation at $37^{\circ} \mathrm{C}$ with gentle shaking for 1 hour. The bacterial suspensions were pelleted via centrifugation at $18,900 \times$ g, washed $3 \times$ with $\mathrm{PBS}$ and resuspended with $100 \mu \mathrm{l}$ of $50 \mathrm{mM}$ Tris, $100 \mathrm{mM} \mathrm{NaCl}, 5 \mathrm{mM} \mathrm{CaCl}_{2}$ ) with $3 \mu \mathrm{g}$ fibronectin (BD Biosciences) and incubation at $37^{\circ} \mathrm{C}$ with gentle shaking for 24 hours. After the incubation was complete, bacteria were pelleted via centrifugation at $18,900 \times \mathrm{g}$ and the supernatants were solublized by boiling in $2 \times$ SDS-PAGE sample buffer containing 2-mercaptoethanol. Samples were subjected to $10 \%$ SDS-PAGE and then electrophoretically transferred to a PVDF membrane (Immobilon-P, Millipore). The PVDF membrane was pre-blocked with $1 \%$ BSATBST for 1 hour at RT to minimize non-specific protein binding, and was then incubated with sheep anti-human fibronectin-specific antibody (diluted 1:2000 in 1\% BSATBST) for 1 hour at RT with gentle rocking. The PVDF membrane was washed three times with TBST to remove unbound primary antibody. The membrane was then incubated in a solution of anti-sheep/goat IgG monoclonal antibody (GT-34, diluted 1:5000 in 1\%BSATBST) with rocking for $1 \mathrm{hr}$ at RT. The PVDF membranes were washed 3 times with TBST to remove unbound secondary antibody. The blot was developed using Pierce PicoWest chemiluminescence reagents and images were captured using a Bio-Rad ChemiDoc XRS system.

\section{Far-Western blotting analysis}

Approximately $100 \mu \mathrm{g}$ of each protein fraction was precipitated using ice-cold acetone, pelleted via centrifugation at $18,900 \times \mathrm{g}$ for 15 minutes, and air-dried at room temperature. The samples were then solublized by boiling in $1 \times$ SDS-PAGE sample buffer containing 2-mercaptoethanol. Duplicate $20 \mu \mathrm{L}$ aliquots of each sample were subjected to $15 \%$ SDS-PAGE to separate the proteins based on their size. One set of the samples was then electrophoretically transferred to a PVDF membrane (Immobilon-Psq, Millipore). The PVDF membrane was pre-blocked with 1\% BSA-TBST for 1 hour at room temperature to minimize non-specific protein binding and was then incubated in a solution of huPLG (3 ug/mL in 1\% BSA-TBST) for one hour with rocking 
at $37^{\circ} \mathrm{C}$. Unbound PLG was removed by washing three times with TBST. Sheep anti-human PLG-specific antibody (diluted 1:2,000 in 1\% BSA-TBST) was added $(100 \mu \mathrm{L} /$ well $)$ and allowed to incubate for 1 hour at $\mathrm{RT}^{\circ}$ with rocking. The PVDF membrane was washed three times with TBST to remove unbound primary antibody. The membrane was then incubated in a solution of anti-sheep/goat IgG monoclonal antibody (GT-34, diluted 1:5,000 in 1\%BSA-TBST) with rocking for $1 \mathrm{hr}$ at room temperature. The PVDF membranes were washed three times with TBST to remove unbound secondary antibody. The blot was developed using Pierce PicoWest chemiluminescence reagents and imaged using a Bio-Rad ChemiDoc XRS system.

\section{Proteomic identification of PLG-binding FT proteins}

Protein bands were excised from Coomassie-stained SDS-PAGE gels, cut into small pieces, incubated in 50\% acetonitrile/100 mM ammonium bicarbonate until colorless, and dried via vacuum centrifugation. The protein was digested by adding $20 \mu \mathrm{l}$ of a $20 \mathrm{ng} / \mu \mathrm{l}$ trypsin solution and incubating overnight at $37^{\circ} \mathrm{C}$. Peptides were extracted from the gel slices via sonication in $50 \mu \mathrm{l} 60 \%$ acetonitrile/5\%TFA, dried via vacuum centrifugation, and reconstituted in $15 \mu \mathrm{l} 0.1 \%$ TFA. Tryptic peptides were desalted/enriched using a C18 ZipTip column (Millipore, Billerica, MA) according to manufacturer's instructions and the eluant was spotted on a MALDI plate and dried. Samples were analyzed using a MALDI-LTQ mass spectrometer (ThermoFinnigan, San Jose, CA). A full MS scan in high-mass range $(\mathrm{m} / \mathrm{z} 600-$ 4000, 5 microscans) was performed. The 50 most intense peaks in the full MS spectrum were selected, and MSMS scans were performed for those ions in high-mass range ( $\mathrm{m} / \mathrm{z}$ 50-4000, 5 microscans), the normalized collision energy for MSMS was 35 . Xcalibur software was used to process the mass spectrometric data, and the NCBInr database and the Bioworks 3.2 search engine software were used for database searching.

\section{Acknowledgements \\ The project described was supported by NIH grant \#U54 Al057157 from Southeastern Regional Center of Excellence for Emerging Infections and Biodefense, by NIH grants Al074582 and Al079482 (to JEB) and Al061260 (to MAM), and by Department of Defense Army grant W81XHW-05-1-0227. The authors also thank Cory Blackwell and Himangi Jayakar for helpful discussions. We also thank Jyothi Parvathareddy, and Janice Collum for their technical assistance.}

\section{Authors' contributions}

SRC conceived and performed all of the experimental work for the study and drafted the manuscript. JEB, TPH, and MAW both participated in the design of the study and played an important role in drafting the manuscript. MAM participated in the design and coordination of all studies, performed the statistical analyses, and helped to draft the manuscript. All authors read and approved the final manuscript.
Received: 10 August 2009 Accepted: 12 March 2010

Published: 12 March 2010

\section{References}

1. Hoel T, Scheel O, Nordahl SH, Sandvik T: Water- and airborne Francisella tularensis biovar palaearctica isolated from human blood. Infection 1991, 19(5):348-350.

2. Siret V, Barataud D, Prat M, Vaillant V, Ansart S, Le Coustumier A, Vaissaire J, Raffi F, Garre M, Capek I: An outbreak of airborne tularaemia in France, August 2004. Euro Surveill 2006, 11(2):58-60.

3. Feldman KA, Enscore RE, Lathrop SL, Matyas BT, McGuill M, Schriefer ME, Stiles-Enos D, Dennis DT, Petersen LR, Hayes EB: An outbreak of primary pneumonic tularemia on Martha's Vineyard. N Engl J Med 2001, 345(22):1601-1606.

4. Syrjala H, Kujala P, Myllyla V, Salminen A: Airborne transmission of tularemia in farmers. Scand J Infect Dis 1985, 17(4):371-375.

5. Francis E: Landmark article April 25, 1925: Tularemia. By Edward Francis. JAMA 1983, 250(23):3216-3224.

6. Hopla CE: The ecology of tularemia. Adv Vet Sci Comp Med 1974 18(0):25-53.

7. Tularemia transmitted by insect bites-Wyoming, 2001-2003. MMWR Morb Mortal Wkly Rep , 2005/02/25 2005, 54:170-173.

8. Eliasson H, Lindback J, Nuorti JP, Arneborn M, Giesecke J, Tegnell A: The 2000 tularemia outbreak: a case-control study of risk factors in diseaseendemic and emergent areas, Sweden. Emerg Infect Dis 2002, 8(9):956-960.

9. Skierska B: [Mosquitoes in the northern part of Szczecin region and their role in epidemiology of tularemia.]. Biul Panstw Inst Med Morsk Trop J W Gdansku 1955, 6:267-275.

10. Hubalek Z, Treml F, Halouzka J, Juricova Z, Hunady M, Janik V: Frequent isolation of Francisella tularensis from Dermacentor reticulatus ticks in an enzootic focus of tularaemia. Med Vet Entomol 1996, 10(3):241-246.

11. Emmons RW, Ruskin J, Bissett ML, Uyeda DA, Wood RM, Lear CL: Tularemia in a mule deer. J Wildl Dis 1976, 12(3):459-463.

12. Greco D, Ninu E: A family outbreak of tularemia. Eur J Epidemiol 1985, 1(3):232-233.

13. Golovliov I, Baranov V, Krocova Z, Kovarova H, Sjostedt A: An attenuated strain of the facultative intracellular bacterium Francisella tularensis can escape the phagosome of monocytic cells. Infect Immun 2003, 71(10):5940-5950.

14. Clemens DL, Lee BY, Horwitz MA: Francisella tularensis enters macrophages via a novel process involving pseudopod loops. Infect Immun 2005, 73(9):5892-5902.

15. Forestal CA, Malik M, Catlett SV, Savitt AG, Benach JL, Sellati TJ, Furie MB: Francisella tularensis has a significant extracellular phase in infected mice. J Infect Dis 2007, 196(1):134-137.

16. Yu JJ, Raulie EK, Murthy AK, Guentzel MN, Klose KE, Arulanandam BP: The presence of infectious extracellular Francisella tularensis subsp. novicida in murine plasma after pulmonary challenge. Eur J Clin Microbiol Infect Dis 2008, 27(4):323-325.

17. Ben Nasr A, Haithcoat J, Masterson JE, Gunn JS, Eaves-Pyles T, Klimpel GR: Critical role for serum opsonins and complement receptors CR3 (CD11b/ CD18) and CR4 (CD11C/CD18) in phagocytosis of Francisella tularensis by human dendritic cells (DC): uptake of Francisella leads to activation of immature DC and intracellular survival of the bacteria. J Leukoc Biol 2006, 80(4):774-786.

18. Barker JH, McCaffrey RL, Baman NK, Allen LA, Weiss JP, Nauseef WM: The role of complement opsonization in interactions between $\mathrm{F}$. tularensis subsp. novicida and human neutrophils. Microbes Infect 2009, 11(8-9):762-9.

19. Sandstrom G, Lofgren S, Tarnvik A: A capsule-deficient mutant of Francisella tularensis LVS exhibits enhanced sensitivity to killing by serum but diminished sensitivity to killing by polymorphonuclear leukocytes. Infect Immun 1988, 56(5):1194-1202.

20. Ben Nasr A, Klimpel GR: Subversion of complement activation at the bacterial surface promotes serum resistance and opsonophagocytosis of Francisella tularensis. J Leukoc Biol 2008, 84(1):77-85.

21. Lahteenmaki K, Kuusela P, Korhonen TK: Bacterial plasminogen activators and receptors. FEMS Microbiol Rev 2001, 25(5):531-552.

22. Sun $\mathrm{H}$ : The interaction between pathogens and the host coagulation system. Physiology (Bethesda) 2006, 21:281-288. 
23. Lahteenmaki K, Edelman S, Korhonen TK: Bacterial metastasis: the host plasminogen system in bacterial invasion. Trends Microbiol 2005, 13(2):79-85.

24. Degen JL, Bugge TH, Goguen JD: Fibrin and fibrinolysis in infection and host defense. J Thromb Haemost 2007, 5(Suppl 1):24-31.

25. Li Z, Ploplis VA, French EL, Boyle MD: Interaction between group A streptococci and the plasmin(ogen) system promotes virulence in a mouse skin infection model. J Infect Dis 1999, 179(4):907-914.

26. Coleman JL, Gebbia JA, Piesman J, Degen JL, Bugge TH, Benach JL: Plasminogen is required for efficient dissemination of B. burgdorferi in ticks and for enhancement of spirochetemia in mice. Cell 1997, 89(7):1111-1119.

27. Sodeinde OA, Subrahmanyam YV, Stark K, Quan T, Bao Y, Goguen JD: A surface protease and the invasive character of plague. Science 1992, 258(5084):1004-1007.

28. Hazlett KR, Caldon SD, McArthur DG, Cirillo KA, Kirimanjeswara GS, Magguilli ML, Malik M, Shah A, Broderick S, Golovliov I, et al: Adaptation of Francisella tularensis to the mammalian environment is governed by cues which can be mimicked in vitro. Infect Immun 2008, 76(10):4479-4488.

29. Filip C, Fletcher G, Wulff JL, Earhart CF: Solubilization of the cytoplasmic membrane of Escherichia coli by the ionic detergent sodium-lauryl sarcosinate. J Bacteriol 1973, 115(3):717-722.

30. Friberg N, Carlson P, Kentala E, Mattila PS, Kuusela P, Meri S, Jarva H: Factor $\mathrm{H}$ binding as a complement evasion mechanism for an anaerobic pathogen, Fusobacterium necrophorum. J Immunol 2008, 181(12):8624-8632.

31. Verma A, Hellwage J, Artiushin S, Zipfel PF, Kraiczy P, Timoney JF, Stevenson B: LfhA, a novel factor H-binding protein of Leptospira interrogans. Infect Immun 2006, 74(5):2659-2666.

32. Hellwage J, Meri T, Heikkila T, Alitalo A, Panelius J, Lahdenne P, Seppala IJ, Meri S: The complement regulator factor $\mathrm{H}$ binds to the surface protein OspE of Borrelia burgdorferi. J Biol Chem 2001, 276(11):8427-8435.

33. Horstmann RD, Sievertsen HJ, Knobloch J, Fischetti VA: Antiphagocytic activity of streptococcal $\mathrm{M}$ protein: selective binding of complement control protein factor H. Proc Natl Acad Sci USA 1988, 85(5):1657-1661.

34. Ram S, Sharma AK, Simpson SD, Gulati S, McQuillen DP, Pangburn MK, Rice PA: A novel sialic acid binding site on factor $\mathrm{H}$ mediates serum resistance of sialylated Neisseria gonorrhoeae. J Exp Med 1998, 187(5):743-752.

35. Bergmann S, Rohde M, Chhatwal GS, Hammerschmidt S: Characterization of plasmin(ogen) binding to Streptococcus pneumoniae. Indian J Med Res 2004, 119(Suppl):29-32.

36. Sun $H$, Ringdahl U, Homeister JW, Fay WP, Engleberg NC, Yang AY, Rozek LS, Wang X, Sjobring U, Ginsburg D: Plasminogen is a critical host pathogenicity factor for group A streptococcal infection. Science 2004, 305(5688):1283-1286.

37. Espersen F: Interactions between human plasma proteins and cell wall components of Staphylococcus aureus. Dan Med Bull 1987, 34(2):59-69.

38. Hauck CR, Ohlsen K: Sticky connections: extracellular matrix protein recognition and integrin-mediated cellular invasion by Staphylococcus aureus. Curr Opin Microbiol 2006, 9(1):5-11.

39. Josefsson E, Higgins J, Foster TJ, Tarkowski A: Fibrinogen binding sites P336 and Y338 of clumping factor A are crucial for Staphylococcus aureus virulence. PLOS ONE 2008, 3(5):e2206.

40. Menzies BE: The role of fibronectin binding proteins in the pathogenesis of Staphylococcus aureus infections. Curr Opin Infect Dis 2003, 16(3):225-229.

41. Agarwal S, Kulshreshtha P, Bambah Mukku D, Bhatnagar R: alpha-Enolase binds to human plasminogen on the surface of Bacillus anthracis. Biochim Biophys Acta 2008, 1784(7-8):986-994.

42. Fricke B, Drossler K, Willhardt I, Schierhorn A, Menge S, Rucknagel P: The cell envelope-bound metalloprotease (camelysin) from Bacillus cereus is a possible pathogenic factor. Biochim Biophys Acta 2001, 1537(2):132-146.

43. Kunert A, Losse J, Gruszin C, Huhn M, Kaendler K, Mikkat S, Volke D, Hoffmann R, Jokiranta TS, Seeberger $H$, et al: Immune evasion of the human pathogen Pseudomonas aeruginosa: elongation factor Tuf is a factor $\mathrm{H}$ and plasminogen binding protein. J Immunol 2007, 179(5):2979-2988.

44. Suomalainen M, Haiko J, Ramu P, Lobo L, Kukkonen M, WesterlundWikstrom B, Virkola R, Lahteenmaki K, Korhonen TK: Using every trick in the book: the Pla surface protease of Yersinia pestis. Adv Exp Med Biol 2007, 603:268-278.

45. Kraiczy P, Hartmann K, Hellwage J, Skerka C, Kirschfink M, Brade V, Zipfel PF, Wallich $\mathrm{R}$, Stevenson B: Immunological characterization of the complement regulator factor $\mathrm{H}$-binding CRASP and Erp proteins of Borrelia burgdorferi. Int J Med Microbiol 2004, 293(Suppl 37):152-157.

46. Kraiczy P, Hellwage J, Skerka C, Becker H, Kirschfink M, Simon MM, Brade V, Zipfel PF, Wallich R: Complement resistance of Borrelia burgdorferi correlates with the expression of BbCRASP-1, a novel linear plasmidencoded surface protein that interacts with human factor $\mathrm{H}$ and $\mathrm{FHL}-1$ and is unrelated to Erp proteins. J Biol Chem 2004, 279(4):2421-2429.

47. Kraiczy P, Hellwage J, Skerka C, Kirschfink M, Brade V, Zipfel PF, Wallich R: Immune evasion of Borrelia burgdorferi: mapping of a complementinhibitor factor $\mathrm{H}$-binding site of BbCRASP-3, a novel member of the Erp protein family. Eur J Immunol 2003, 33(3):697-707.

48. Kraiczy P, Skerka C, Brade V, Zipfel PF: Further characterization of complement regulator-acquiring surface proteins of Borrelia burgdorferi. Infect Immun 2001, 69(12):7800-7809.

49. Kraiczy P, Skerka C, Zipfel PF, Brade V: Complement regulator-acquiring surface proteins of Borrelia burgdorferi: a new protein family involved in complement resistance. Wien Klin Wochenschr 2002, 114(13-14):568-573.

50. Wallich R, Pattathu J, Kitiratschky V, Brenner C, Zipfel PF, Brade V, Simon MM, Kraiczy P: Identification and functional characterization of complement regulator-acquiring surface protein 1 of the Lyme disease spirochetes Borrelia afzelii and Borrelia garinii. Infect Immun 2005, 73(4):2351-2359.

51. Fenno JC, Tamura M, Hannam PM, Wong GW, Chan RA, McBride BC: Identification of a Treponema denticola OppA homologue that binds host proteins present in the subgingival environment. Infect Immun 2000, 68(4):1884-1892

52. Crane DD, Warner SL, Bosio CM: A novel role for plasmin-mediated degradation of opsonizing antibody in the evasion of host immunity by virulent, but not attenuated, Francisella tularensis. J Immunol 2009, 183(7):4593-4600.

53. de Bruin OM, Ludu JS, Nano FE: The Francisella pathogenicity island protein IgIA localizes to the bacterial cytoplasm and is needed for intracellular growth. BMC Microbiol 2007, 7:1.

doi:10.1186/1471-2180-10-76

Cite this article as: Clinton et al:: Binding and activation of host plasminogen on the surface of Francisella tularensis. BMC Microbiology $201010: 76$

\section{Submit your next manuscript to BioMed Central and take full advantage of:}

- Convenient online submission

- Thorough peer review

- No space constraints or color figure charges

- Immediate publication on acceptance

- Inclusion in PubMed, CAS, Scopus and Google Scholar

- Research which is freely available for redistribution

Submit your manuscript at www.biomedcentral.com/submit
C Biomed Central 